\title{
O SISTEMA DE CONSELHOS \\ COMO UMA FORMA DE ATUAÇÃO NA POLÍTICA
}

\section{Cláudio Thiago Vieira Matta}

Advogado, Mestrando pela Fundação UNIVEM-Marília

e-mail: thimatta@hotmail.com.

RESUMO: O desaparecimento entre o mundo público e privado; a perda da ação política no mundo contemporâneo, evidenciada pelos grandes regimes totalitários surgidos no século vinte; a ação do homem perante a perda da referência histórica; um breve esboço deste processo histórico, seus desdobramentos e conseqüências, relacionados com os Sistemas de Conselhos; a utilidade destes no mundo atual: estes são os objetivos do presente trabalho.

PALAVRAS-CHAVE: Perda entre o público e privado; Ação política; Sistema de conselhos. 


\section{ENTRE O PASSADO E O FUTURO}

O presente trabalho tem por objetivo analisar superficialmente o "fio condutor" dos escritos da Hannah Arendt, que de certa forma encontram-se presentes em todos os seus trabalhos: a crise do mundo contemporâneo. Esta crise que se instaura após a perda da tradição e ao modo de pensar político, no plano intelectual, e a do esfacelamento do espaço da liberdade e felicidade pública na esfera social, ou seja, a perda entre o público e o privado.

A autora analisa em The origins of totalitarianism a experiência totalitária por qual passou a Europa e demonstra que a experiência totalitária só aconteceu devido à crise no espírito humano, marcado pelo desenraizamento do homem e seu conseqüente desligamento com a tradição. ${ }^{1}$

Assim, compreendeu a autora que os regimes totalitários eram um desdobramento histórico que havia afetado toda a Europa e, por conseqüência, havia instaurado uma ruptura com o pensamento político tradicional do ocidente.

Destarte, surge uma lacuna entre o passado e o futuro, ou seja, como estamos vivendo o presente, esta crise, que se traduz principalmente pelo esfacelamento da cultura, com a conseqüente perda da sabedoria, na qual a história não fornece mais padrões morais, e as categorias políticas do presente servem tampouco para as referências das ações no mundo.

Para a autora, Marx, Kierkegard e Nietzsche anteciparam a crise que estaria por emergir. Segundo eles, esta crise estaria relacionada com a linguagem pela qual o homem não mais se encontra como os objetos que ele próprio criou, a linguagem para explicar sua relação com o mundo agora é insuficiente.

Nietzsche caracterizava o homem pela ânsia ao poder e por sua produtividade, diferentemente dos gregos, que caracterizavam o homem por sua condição de ser racional. Por sua vez, Marx defendeu uma incompatibilidade entre o pensamento clássico e as condições políticas da modernidade, trazidas pelas revoluções Industrial e Francesa. As modificações se dão mediante conceitos básicos: a) o trabalho cria o homem, ou seja, o homem cria a si mesmo, e sua diferença em relação a outros animais e ser animal laborans e não rationale; b) a

\footnotetext{
${ }^{1} \mathrm{O}$ conceito de tradição é o de transmissão lógica plural que fornece parâmetros para o homem agir.
} 
violência e a parteira da História uma contestação à faculdade específica do homem, que seria a de conduzir os negócios da polis por meio da palavra, pois o uso da violência seria aplicável em última instância; e c) a atualização da Filosofia na Política, que implica o fim de um ciclo de pensamento, iniciado quando Platão se afastou da Política para retornar a ela impondo seus padrões, e quando Marx se afastou da Filosofia para realizá-la na Política.

Segundo Arendt, esse modo de pensar trazido por Marx resultou em profundas modificações no conceito de História, que deve ser compreendido para uma melhor avaliação entre a modernidade e a tradição.

Segundo os helenos, tudo no mundo seguia uma eterna transição entre o Ser e o não Ser, de modo que todas as coisas nasciam e pereciam em um fluxo eterno que se entendia ser o próprio substrato da imortalidade. Mas os homens se encontravam conscientes de sua própria condição de mortais, já que a natureza simplesmente é, enquanto o homem tem a "consciência de Ser". Destarte, um homem heleno só se tornaria imortal pelos seus grandes feitos, e somente a vida pública concedia a possibilidade de tais feitos. O conceito de História era 0 de imortalizar estes atos e registrá-los para a posteridade, conforme entendiam os helenos.

Entretanto, para Vico e Hegel a importância da História é teórica, uma visão a posteriori dos acontecimentos, na qual o historiador, após observar a totalidade do processo, consegue compreendê-lo. Nas palavras de Hegel, no prefácio à sua Filosofia do Direito: "a coruja de Minerva voa só no cair da tarde, quando uma forma de vida já envelheceu". Por usa vez, Marx, ao propor a atualização da Filosofia na Política, subverteu seu significado teórico, pois sua Filosofia Política se baseia não numa análise da ação, mas na preocupação hegeliana com a História, mas uma História que fornece uma projeção para o futuro, e não mais apenas uma compreensão do passado, e sua finalidade seria a atualização da idéia de liberdade.

Segundo Marx, esse processo seria revelado pelas leis da dialética, e o seu conteúdo seria a luta de classes. Esse processo compreende começo meio e fim, e o fim seria a sociedade perfeita. Assim, o processo, quando termina, torna irrelevante todo o resto que o antecedeu. Segundo Arendt, em última análise, a atualização da Filosofia na Política esbarra numa situação paradoxal: a sociedade perfeita implicará o fim do trabalho, com o advento do ócio, no fim da violência, com o desaparecimento do Estado, e no fim do pensamento, quando este tiver se realizado na História. Aqui ocorre o desencontro entre os conceitos de animal 
laborans, da violência e da atualização da Filosofia e a visão final de uma sociedade sem Estado, sem trabalho e sem classes.

Obviamente, uma sociedade como esta ainda está bem longe de se realizar, contudo, a influência do pensamento de Marx, conjuntamente com o de Kierkegard e Nietzsche, no pensamento contemporâneo foi definitiva, e, por isso, deve ser salientada na análise da ruptura com a tradição.

Estes autores tentaram apresentar a tradição como uma totalidade, contudo, contribuíram para o desaparecimento de uma visão totalizadora da tradição. Assim, nos modelos científicos modernos tudo pode eventualmente funcionar. A idéia de modelo mudou a noção de teoria, e esta deixou de ser um sistema de verdades interligadas que não foram feitas, mas dadas pela razão, e os sentidos se transformaram em numa hipótese de trabalho cuja validez depende não de uma revelação de verdade, mas do fato de funcionar, assim, no mundo teórico e prático, tudo pode acontecer, e o totalitarismo é a prova disso. A circularidade entre os fatos e as teorias, na qual a tradição não possui mais padrões para julgá-las devido à perda do senso comum e destruição dos valores, tampouco perguntas para explicála, em virtude da noção contemporânea de teoria.

Destarte, a análise histórica e o pensamento político permitiram crer que, embora de modo indefinido e genérico, a estrutura essencial de toda a civilização atingiu seu ponto de ruptura. Mesmo quando aparentemente preservada em alguns lugares do mundo, essa estrutura não autoriza antever a futura evolução da humanidade, e tampouco oferece explicações adequadas aos seus horrores.

Caminhar neste terreno movediço - a lacuna entre o passado e o futuro, que significa a perda da sabedoria - é o objetivo da reflexão política de Hannah Arendt.

\section{O ESPAÇO DA PALAVRA E DA AÇÃO}

A próxima análise tenta compreender como deve se dar a ação política neste contexto. Arendt compreende o campo da ação política diferentemente de Platão, que o colocava na razão pura, ou de Kant, que o colocava na razão prática. Segundo a autora, ambos pecavam por inserir a ação política em um "monólogo"; o pensamento deve se dar no plural. Assim, apesar da crítica a Kant, a autora acaba se utilizando de um conceito kantiano, um pensar no plural - mentalidade alargada - 
uma concordância com os outros, logo não é um juízo universal, possui uma validade específica e limitada ao diálogo humano.

Outro problema que surge é a relação entre a verdade e a Política. $\mathrm{Na}$ Política, existe uma verdade factual, que se apresenta como não necessária, podendo estar revestida do erro ou da mentira. Esta situação provoca um ceticismo, pois permite a persuasão e a violência, que podem destruir a verdade factual, daí a importância de mecanismos que defendem a verdade factual como uma universidade autônoma e um Judiciário independente.

A liberdade apresenta-se como um problema central na Política a partir da qual agimos, diferentemente do pensamento no qual nada vem do nada, existindo um diálogo consigo mesmo.

Já a ausência ou não da liberdade só se percebe no diálogo plural. A política e a liberdade são coincidentes, porém se articulam somente quando existente um mundo público. Ação não se reduz à vontade e intelecto, outros princípios como as virtudes também a orientam. As Instituições são feitas por ações, o Estado é produto da ação e não da teoria, ou seja, do pensamento, embora este o influencie fortemente.

Assim, se a política é produto da ação, o que seria o agir? Agir deriva do verbo agere (pôr em movimento, fazer avançar) e gerere (criar, trazer), que para a presente análise pode ser captado pelo particípio passado gestum, que origina gesta. Agir seria movimentar-se para trazer gestas. Assim, agir exprime uma atividade em exercício contínuo, em contraste com facere, que é uma atividade executada num instante. A ação política seria um exercício contínuo, uma criatividade da ação política que faz avançarem e viverem as instituições.

Atualmente, os feitos e acontecimentos que resultam da ação inserem-se num contexto cujo sentido nos é fornecido a partir do conceito de autoridade. Essa palavra deriva do verbo latino augere (aumentar, acrescentar). Na análise da Política clássica, Aristóteles e Platão pecaram por terem analisado as relações a partir do pai e do filho, senhor e escravo, que não eram relações entre iguais, como as que devem guiar a vida política.

A busca do sentido de autoridade deve ser remetida à Roma. Autoridade exclui coerção, porque envolve obediência, e por envolver obediência está no campo da hierarquia, que exclui a persuasão igualitária, a qual anima o diálogo político. 
Contudo, existe um momento em que é necessário no processo político uma escolha. Esse momento é o poder, que por sua vez deve ter legitimidade, e esta deriva da ação conjunta, cuja existência se encontra na comunidade política.

Assim, o melhor exemplo seria Roma: o poder estava com o povo, mas a autoridade residia no Senado, que era incumbido de zelar pela continuidade da fundação de Roma, ou seja, a autoridade estava no Senado.

Todavia, qual o conceito de autoridade no mundo contemporâneo, onde tudo está desagregado? A relevância dessa questão encontra-se na freqüência do fenômeno revolucionário, que, a partir das revoluções Americana e Francesa, buscou instituir um novo ato que legitimasse a fundação e a comunidade política e preenchesse a lacuna entre passado e futuro.

Assim como aponta Políbio - "O começo não é apenas metade do todo mas alcança o fim" -, sugere Arendt que o princípio da verdade factual que estrutura a liberdade pública informa o discurso dialógico da Política. Destarte, a experiência das revoluções em sua fundação deixa de ser passado para se lançar ao futuro, legitimando a violência, como já afirmavam Robiespiere e Maquiavel.

Logo, o problema atual é que as revoluções não conseguiram implementar a liberdade que fundou a sociedade, isso devido a um obscurecimento entre o público e o privado, ou seja, as revoluções não asseguraram a felecidade pública, porque não mantiveram um espaço público onde a liberdade aparecesse na coincidência entre ação, palavra vivida e palavra viva. lluminar este setor público foi o estudo ao qual Hannah Arendt dedicou seu pensamento: comunicação limitada e sem fronteiras, que é a forma de revelação da verdade; não exprime verdade, mas instaura e se liga no diálogo político. Esta é uma característica de seu pensamento, diferentemente das imputações dogmáticas que lhe foram atribuídas. A liberdade readquire importância, apesar do totalitarismo, do impasse do pensamento contemporâneo e da perda do público privado.

Por outro lado, cabe ressaltar que a nossa época interligou de modo tão estranho o bem e o mau, que sem a expansão do imperialismo, levado adiante por mero amor à expansão, o mundo jamais se teria tornado um só. Sem o mecanismo político da burguesia que implantou o poder pelo amor ao poder, as dimensões da força do homem não poderiam nunca terem sido descobertas, e sem a realidade fictícia dos movimentos totalitários pelo louvor por amor à força, as incertezas 
essenciais do nosso tempo acabaram sendo desnudadas com uma clareza sem a qual poderíamos ter sido levados à ruína, sem jamais saber o que estava acontecendo.

Assim, o antissemitismo, não apenas o ódio aos judeus, o imperialismo, não apenas a conquista, e o totalitarismo, um após o outro, um mais cruel que o outro, demonstram que a dignidade do homem precisa de novas garantias, somente encontráveis em novos princípios políticos, em uma nova lei da terra, cuja vigência, desta vez, alcance a todos e cujo poder seja estruturado, limitado e controlado por entidades territoriais novas, pois já não podemos extrair aquilo que foi bom no passado e simplesmente o chama de herança, deixar de lado o mau e esperar o esquecimento.

A corrente subterrânea da História veio à tona e usurpou a dignidade de nossa tradição. Essa é a realidade em que vivemos, e por isso não nos podemos refugiar na nostalgia de um passado evoluído e intacto ou num antecipado futuro melhor.

Neste sentido é que o pluralismo jurídico poderá lançar novas diretrizes para uma efetiva ação política, não tendo mais o Estado como centro único do poder político e fonte exclusiva de todo Direito. Assim, uma nova perspectiva se lança ao mundo contemporâneo, uma perspectiva descentralizadora e anti-dogmática que pleiteia a supremacia de fundamentos éticos, políticos e sociológicos sobre os existentes critérios tecno-formais positivistas.

Devemos ter em vista os "novos atores que entram em cena" e o conjunto de necessidades fundamentais que os legitimam para reivindicar seus direitos. Logo, deve-se ter em mente um novo pluralismo de dimensões política e jurídica, que viabilize uma democracia participativa e descentralizada dos espaços comunitários.

Esta reorganização política participativa é algo difícil de ser feita em um curto espaço de tempo, sobretudo em culturas latino-americanas enraizadas em uma tradição política cultural centralizadora, dependente e autoritária. Basta lembrar a política do coronelismo, do clientismo ou mesmo as políticas paternalistas e autoritárias e muitas vezes intervencionistas do Estado, nas quais o poder centralizador se projeta para efetivar as modificações independentes da participação dos setores locais, regionais e de legitimar o espaço público para a negociação entre as oligarquias rurais e as burguesias estrangeiras, e, assim, assegurar o consenso 
dos subordinados por meio de uma política de cooptação e de distribuição clientilística de favores.

Destarte, uma mudança com uma proposta de ruptura como a citada estrutura política demanda complexas transformações nas práticas sociais, na cultura e nos valores de cada sociedade. Importa também reordenar os espaços públicos individual e coletivo, resgatando formas de ação humana que passam pelas questões da "comunidade", "políticas democráticas de base", "participação e controle popular", "gestão descentralizada", "poder local ou municipal" e "sistema de conselhos".

Em especial, gostaríamos de dedicar especial atenção ao sistema de conselhos, não por crer que os outros sistemas não tenham importância, pois há uma inter-relação necessária entre eles. É necessário ter um novo paradigma do político e do social e sobre as formas alternativas de legitimidade a partir de novos sujeitos coletivos, e aqui reside a importância de se recuperar o valor da comunidade, o mesmo ocorrendo com as políticas democráticas de base, que devem fortalecer os membros das comunidades neste "novo agir político" dando-lhe as bases para o agir comunitário, não se esquecendo da importância da participação e do controle popular por meio, principalmente, do referendum e do plebiscito.

Em síntese, o espaço público comunitário alcançará um novo significado somente se houver novas formas democráticas, com uma participação política de base. Isso não implica um total abandono do velho modelo democrático representativo burguês e suas limitadas regras institucionais formais, como os partidos políticos, mas sim um desenvolvimento de formas democráticas de base, como a participação, a gestão compartida e o sistema de conselhos, capazes de conviver em certos institutos positivos da democracia por delegação. Assim, o que se propõe é uma nova forma de convergência, que respeite a participação, o controle e a representação vinculante dos interesses de todos os setores da sociedade, que seja sob a experiência de sujeitos individuais e a expressão de sujeitos coletivos. Logo, sugere-se um alargamento da democracia, uma maior participação, um processo de expansão do poder ascendente, um controle de baixo para cima em suas diversas articulações, desde a família até o trabalho, chegando aos diferentes setores públicos. 
Contudo, a realidade nos mostra pessoas consumidoras, uma gritante desigualdade social e econômica, e diante disso, a participação democrática é totalmente comprometida, somado às múltiplas formas de vida cotidiana, que são permanentemente coladas numa continuidade acelerada, as formas como o próprio sufrágio ou a democracia formal acabam se perdendo rapidamente, sobretudo diante do poder econômico ou da manipulação da mídia, com os determinados modelos culturais sendo passados como referências a serem seguidas.

Nesse sentido, a democracia participativa de base não se fixa tanto em número de votos, mas nas necessidades de cada comunidade por meio da opinião direta das diferentes comunidades. É neste sentido que a forma mais direta de participação democrática é o sistema de conselhos, existentes nos mais diferentes meios públicos da sociedade, como o conselho de bairro, os comitês de fábrica, as comissões mistas de espécies distintas ou as juntas distritais. Assim se insere uma nova política, composta por uma democracia pluralista descentralizada e assentada na base da participação de base somada ao poder da "autonomia local".

O sistema de conselhos propicia mais facilmente a participação e, por conseguinte, uma maior tomada de decisões e o controle popular no processo de socialização, nos âmbitos do trabalho e da produção e na distribuição e no uso social.

Assim, o espaço público local e sua ordem política e democrática estruturase na forma piramidal dos conselhos, composta por comitês de consultas, deliberação e execução, sendo constituída por uma rede de múltiplas forças sociais distribuídas desde uma escala maior, como Conselhos Comunitários, até níveis menores, como os Conselhos de Bairros.

Percebe-se que, diferentemente do governo dos Conselhos, o núcleo de poder reside no conjunto dos organismos de base, e as decisões tomadas são passadas, asseguradas e executadas para a cúpula administrativa com delegação. Mas quando o sistema está escalonado sob a base de uma pirâmide de poderes difusos, as bases deverão dispor de instrumentos eficazes para opinar, pressionar e controlar os núcleos de decisão e de poder mais acima. Neste ponto, torna-se necessária a recuperação de certos mecanismos de base da democracia representativa, como o modus operandi do sistema piramidal de base. 
Por fim, o "sistema de Conselhos" teve uma alta importância nos eventos mais importantes e transformadores da sociedade, como a Revolução Norte-America e a Revolução Francesa, dentre outras, e continua sendo exaltado por inúmeros teóricos das mais diversas correntes e teorias, como o foi pela própria Hannah Arendt.

Esse sistema lança novas luzes à realidade na qual vivemos, um realidade que nos oferece um mundo fragmentado, cuja maior expressão é a perda de distinção entre ambiente público e privado, podendo se tornar um modelo moderno na modalidade de controle das classes populares sobre a organização do trabalho e da produção, somado a um fator instrumental privilegiado e essencial de expressão dos movimentos sociais.

Assim, a reordenação política do espaço público privado, com o conseqüente processo de democracia descentralizadora e participativa, tem que evidenciar uma sociedade pluralista, marcada por conflitos e diferenças, propiciando uma legitimidade embasada nas necessidades fundamentais de sujeitos coletivos insurgentes, com sua práticas e relações, somada à satisfação de suas reivindicações cotidianas, passando a ser encaradas como produção jurídica não estatal.

\section{BIBLIOGRAFIA}

ARENDT, Hannah. As origens do totalitarismo.

ARENDT, Hannah. A condição humana.

ARENDT, Hannah. A dignidade da Política.

LAFER, Celso. Debates - Entre o Passado e o Futuro. Ed. Unesp.

WOLKMER. Antonio Carlos. Pluralismo Jurídico. Editora Alfa-Omega. São Paulo. 1994. 